\title{
Psychiatric Induced Births in Jamaica: Homicide and Death Effects on Pregnancy
}

\author{
*Paul Andrew Bourne ${ }^{1}$ and Angela Hudson-Davis ${ }^{2}$ \\ ${ }^{1}$ Socio-Medical Research Institute, USA \\ ${ }^{2}$ Capella University, USA
}

Submission: June 24, 2016; Published: August 05, 2016

*Corresponding author: Paul Andrew Bourne, Socio-Medical Research Institute, Kingston, Jamaica.

\begin{abstract}
For this paper, the researchers have narrowed the gap in the health literature by addressing the following.

Objectives: Evaluate the role of homicide on admissions to a maternity hospital (or during pregnancy), Assess whether or not deaths can induce pregnancy or birth, Determine the responsivity of hospitalization at a mental health facility among pregnant women; \& Calculated the responsivity of hospitalization to a maternity institution based on changes in homicide or deaths. The data for this study were taken from a Jamaica Government Publication. Data were also obtained from the Ministry of Health (2005-2015) on admissions to a national mental health public hospital in Jamaica, which is the Bellevue Hospital (referred to as Bellevue). The period for this work is from 2005 through to 2015. Homicide has an effect on admissions to the maternity institution, Victoria Jubilee hospital, using the positive elasticities, especially those greater than one. Pregnancy has an effect on hospitalization to a psychiatric hospital, which means that there are psychiatric induced births in Jamaica.

Keywords: Induced birth; Postpartum psychosis
\end{abstract}

\section{Introduction}

Jamaica is the largest English-Speaking Caribbean nation and the third largest Caribbean island with an estimated population of 2,793,335 people (for 2015, Statistical Institute of Jamaica, 2016; United Nations). It is 4,411 square miles and 146 miles long, 51 miles wide and achieved independence on $6^{\text {th }}$ August 1962. The island is divided into 14 parishes, with the capital of each parish indicated by a red circle or square shown on (Figure 1). The population is served by at least one government hospital in each parish, with certain hospitals being affiliated with the national institution and some extend to the wider EnglishSpeaking Caribbean.

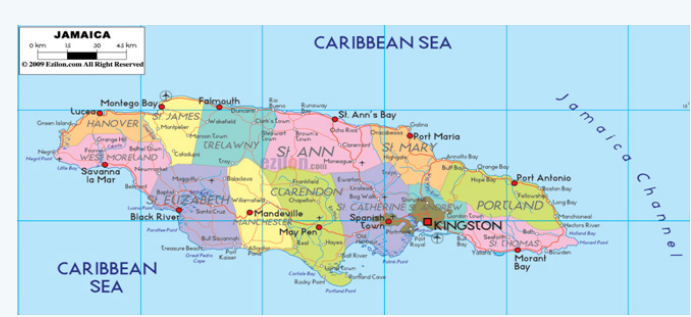

S o u r c e: h t t p s: / / w w w. g o o g l e.com.j m / search?q=map+in+jamaica\&biw

Key: Capital of each parish is marked by a red circle or red square

Figure 1: Map of Jamaica by Parishes.

Some of the island's national hospitals include: Bellevue (i.e., mental health), Victoria Jubilee (i.e. maternity), National Chest
(Tuberculosis), Sir John Golding Rehabilitation (i.e., physical medicine and rehabilitation); Kingston Public (i.e., trauma) \& Bustamante Hospital for Children (i.e., general medicine). Both the Victoria Jubilee and the Bellevue hospitals are located in the parish of Kingston. Victoria Jubilee is on North Street, Western Kingston, and Bellevue is sited on Windward Road, Eastern Kingston, Jamaica. Victoria Jubilee Hospital was established in 1872 and it is the only maternity hospital on the island SERHA [1]; Hall \& Wynter [2]. Bellevue hospital was built and commissioned in 1861. It was initially called the Jamaica Lunatic Asylum, renamed in 1938 as Jamaica Mental Hospital and as the Bellevue hospital in 1946 bellevuehospital.org nd [3].

A search of health literature revealed the following studies that have previously examined postpartum psychosis Bydlowski [4]; Baldur-Felskov et al. [5]; Xu et al. [6]; Crawford et al. [7]; Gold [8]; Thornton, Guendelman \& Hosang [9] among others. Burke et al. [10] found that women tend to be at their peak of prevalence as it relates to psychiatric disorders during their childbearing years. The National Institute for Health [11] outlined that women who have had severe mental health problems are more likely to experience mental health illness during pregnancy. A group of researchers, examining some 1.3 Swedish born between 1973 to 1985 , found that people who were born prematurely were more likely to have mental health problems Gallagher [12], which were similar to that revealed in study Nosarti et al. [13]. 
The researchers did not uncover any practically systematic empirical enquiry aim at untangling the effects of homicide and deaths on admissions to maternity hospital and the relationship between the hospitalization of pregnant women and psychiatric hospitalization. An extensive search of Pub Med, Google scholar and other search engines did unearth any research on the aforementioned issues. Another rationale for this study is based on the comments of Valenca \& de Moraes [14] "There is a scarcity of studies in the literature that deal with the relationship between mental disorders and homicide in developing countries" (S67). Such reality suggests the health literature is lacking on the matter of postpartum psychosis, especially in Jamaica with a homicide rate that is highest in the Caribbean. For this paper, the researchers attempted to bridge the gap in the health literature by addressing the following.

Objectives: Evaluate the role of homicide on admissions to a maternity hospital (or on pregnancy); Assess whether or not deaths can induce pregnancy or birth; Determine the responsivity of hospitalization at a mental health facility among pregnant women \& Calculated the responsivity of hospitalization to a maternity institution based on changes in homicide or deaths.

\section{Theoretical Framework}

Koppensteiner \& Manacorda [15] forwarded an empirical model to establish factors that account for birthweight including homicide. They used a linear model to express that homicide and other factors explain birth, equation (1):

Yiat $=\beta_{0}+\beta_{1} \mathrm{HOM}_{\text {at }}+\mathrm{d}_{\mathrm{a}}+\mathrm{d}_{\mathrm{t}}+\mathrm{u}_{\mathrm{iat}}(1)$

"where $\mathrm{Y}_{\text {iat }}$ is the individual outcome variable (birthweight, gestational length, etc.) in area (municipality or neighborhood) $a$, at time $t, \mathrm{HOM}_{a t}$ is the local homicide rate and $d_{a}$ and $d_{t}$ are respectively mother's area of residence and month of conception-fixed effects, while u is an error term" Koppensteiner \& Manacorda [15]. This paper employs a similar model to explain how homicide or death influences hospitalization at a maternity hospital (i.e., Victoria Jubilee Hospital).

\section{Methods and Materials}

The data for this study were taken from a Jamaica Government Publication; the Ministry of Health reported admissions to Bellevue a national mental health public hospital in Jamaica from 2005 through2015. The timeline for this research work is 2005 through to 2015. Data were recorded, stored and retrieved using the Statistical Packages for the Social Sciences (SPSS) for Windows, Version 24.0. The level of significance that is used to determine statistical significance is less than $5 \%(0.05)$ at the 2-tailed level of significance. Ordinary Least Square (OLS) regression was used to ascertain the correlation between homicide and pregnancy, death and pregnancy, and admissions to a psychiatric and maternity hospital, using R2.

In order to assure the OLS application was appropriate for this study; all the assumptions were tested before usage. In cases where variables are highly inter-correlated ( $r>0.7$ ), tolerance were checked and if multi-collinearity was discovered, one of the variables was dropped and using separately in a model without the highly correlated variable.

Two of the assumptions of OLS were not met, linearity and normality, and so with this violation, OLS was not used Cohen \& Cohen [16]; Hu [17]; Hill et al. [2]; Lewis-Beck [18]; Maddala [19]. Given that the two of the assumptions of OLS were violated, curvilinear analyses were done on the data Cohen \& Cohen [16]; Hu [17]; Hill et al. [2]; Maddala [18]. Whether it is medical research or otherwise, interpreting the correlation coefficients is important Divaris et al. [20]; Hinkle et al. [21]; Mukaka [22] and Evans [23] provided a platform for correlation coefficient interpretations. Evans [23] outlined that for $r$, very weak is 0 0.19 ; weak is $0.20-0.39$; moderate is $0.40-0.59$; strong is 0.60 0.79 and very strong is $0.80-1.00$ as well as for $r 2$ : very weak is 0 $-<4 \%$; weak is $4-16 \%$; moderate is $16-36 \%$; strong is $36-<64 \%$ and very strong is $64-100 \%$. For this study, Evans' perspective will be used to interpret the strength of squared $\mathrm{R}$ values, which is in keeping with similar positions by Howell [24,25]; and Howitt \& Cramer [26].

Having tried to use OLS to model the correlations for this study, it was revealed that they are best expressed by curvilinear relationships and so the models are based on curvilinear functions and their correlations are interpreted by way of Evans and others' works.

Cross-elasticities of hospitalization

( $\% \Delta$ in admissions at national psychiatric hospital (i.e.,Bellevue) ) $/(\% \Delta$ in admissions at national maternity hospital (i.e.,Victoria Jubilee) )

$$
\eta=\frac{\% \Delta \text { in admissions at national psychiatric hospital (i.e.,Bellevue) }}{\% \Delta \text { in admissions at national maternity hospital (i.e.,Victoria Jubilee) }}
$$

Or

$\underline{\text { Difference in Hospitalization at national psychiatric hospital (i.e, Bellevue) at time t and } t+1}$ X 100 $\eta=\frac{\text { Hospitalization at national psychiatric hospital (i.e, Bellevue) at time t }}{\text { Difference in Hospitalization at national maternity hospital (i.e, Victoriajubilee) at time tand } t+1} \times 100$ Hospitalitization at national maternity hospitali (i.e. Victoria Jubilee) at time t

Where $\eta$ is the elasticity of hospitalization

$\% \Delta$ denotes the percentage change in hospitalization at $\mathrm{t}$ and $t+1$, where time $t$ is one year and $t+1$ is the following year.

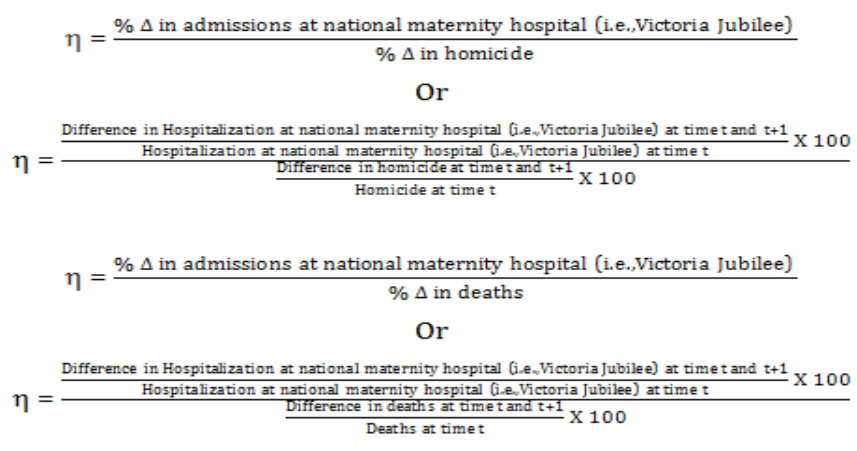

Interpretations of elasticities results: 


\section{Psychology and Behavioral Science International Journal}

$\eta>1$ : elastic hospitalization or highly responsive hospitalization meaning that a one percentage change in the denominator will result in a more than 1 percentage change in the numerator;

$\eta<1$ : inelastic hospitalization or lowly responsive hospitalization which denotes that a one percentage change in the denominator will result in a less than 1 percentage change in the numerator;

Interpreting signs of the elasticities:

Negative sign means substitution effect or one product can operate outside of the other;

Positive sign means complementary effect or one product operates jointly with another

\section{Substitution effect}

$\eta<-1$ : This is a substitution effect that is highly responsive

$\eta<-1$ : This is a substitution effect this is lowly responsive

Note: The rates are displayed in Annex (Table 1).

Table 1: (Annex): Birth rate, death rate, homicide rate and psychiatric hospitalization rate 2006-2015.

\begin{tabular}{|c|c|c|c|c|}
\hline Year & Birth rate/1000 & Death rate/1000 & Homicide rate/100,000 & Psychiatric hospitalization rate/100,000 \\
\hline 2006 & 16.24 & 7.12 & 50.32 & 41.68 \\
\hline 2007 & 16.21 & 7.68 & 58.82 & 36.06 \\
\hline 2008 & 16.04 & 7.43 & 59.58 & 36.17 \\
\hline 2009 & 15.87 & 6.99 & 62.32 & 30.32 \\
\hline 2010 & 15.03 & 7.98 & 52.98 & 38.77 \\
\hline 2011 & 14.69 & 6.27 & 41.67 & 35.45 \\
\hline 2012 & 14.61 & 6.28 & 40.44 & 36.75 \\
\hline 2013 & 13.54 & 5.68 & 44.20 & 36.50 \\
\hline 2014 & 18.41 & 6.67 & 36.94 & 36.94 \\
\hline 2015 & 18.16 & 6.50 & 42.67 & 35.58 \\
\hline
\end{tabular}

\section{Findings}

Table 2: Admissions at Victoria Jubilee hospital, deaths and homicides, 2006-2015.

\begin{tabular}{|c|c|c|c|}
\hline Year & Victoria Jubilee Hospitalizations & Deaths & 18,960 \\
\hline 2006 & 14,101 & 20,550 & 1,340 \\
\hline 2007 & 15,846 & 19,966 & 1,601 \\
\hline 2008 & 14,928 & 18,855 & 21,503 \\
\hline 2009 & 16,635 & 1,680 & 1,926 \\
\hline 2010 & 15,885 & 1,428 & 1,998 \\
\hline 2011 & 15,888 & 1,095 \\
\hline 2012 & 16,452 & 1,427 \\
\hline 2013 & 16,895 & 1,200 \\
\hline 2014 & 15,209 & 1,005 \\
\hline
\end{tabular}


Table 2 presents data on annual admissions at Victoria Jubilee hospital (i.e., Nation's maternity hospital), deaths and homicide for Jamaica from 2005-to-2015. Over the 10year period, the average number of admissions to the Victoria Jubilee hospital was 15855 pregnant women \pm 886 pregnant women (95\%CI: 15221-15489 pregnant women) compared to 1324 $\pm 1155-1493$ people murdered (95\%CI: 1155-1493) and 18549 deaths \pm 1829 deaths (95\%CI: 17241-19857deaths). In the first 5-year period (2006-2010), the average number of pregnant women hospitalized Victoria Jubilee hospital was $15479 \pm 980$ pregnant women (95\%CI: 14262-16695 pregnant women) compared to $1525 \pm 138$ people murdered $(95 \% \mathrm{CI}$ :
1354-1696) and 19967 \pm 1112 deaths (95\%CI: 18586-21348 deaths). Comparatively, for the latter 5-year period, the average number of admissions at the Victoria Jubilee hospital was 16230 pregnant women \pm 675 pregnant women (95\%CI: 15391 - 17068 pregnant women) compared to $1123 \pm 80$ people murdered (95\%CI: 1024-1224) and 17131deaths \pm 1123 deaths (95\%CI: 15736-18525 deaths). It should be noted here that the number of pregnant women admitted to the Victoria Jubilee hospital rose by $4.85 \%$ in the latter 5 -year period over the former 5 -year period compared to a $26.36 \%$ decline in murders for the same period.

Table 3: Cross-elasticities of homicide, 2006-2015.

\begin{tabular}{|c|c|c|c|c|c|}
\hline Year & $\begin{array}{c}\text { Diff in } \\
\text { Hospitalization }\end{array}$ & Diff in Homicide & $\mathbf{\%} \boldsymbol{\Delta}$ in admissions atVictoria Jubilee & $\begin{array}{c}\text { \% } \mathbf{\Delta} \text { in } \\
\text { Homicide }\end{array}$ & - \\
\hline 2006 & - & - & - & 17.46 & - \\
\hline 2007 & 1,745 & 234 & 12.38 & 1.72 & -3.3773 \\
\hline 2008 & -918 & 27 & -5.79 & 4.93 & 2.3174 \\
\hline 2009 & 1,707 & 79 & 11.43 & -15.00 & 0.3006 \\
\hline 2010 & -750 & -252 & -4.51 & -21.22 & -0.0009 \\
\hline 2011 & 3 & -303 & 0.02 & -2.67 & -1.3312 \\
\hline 2012 & 564 & -30 & 3.55 & 9.59 & 0.2808 \\
\hline 2013 & 443 & 105 & 2.69 & -16.25 & 0.6141 \\
\hline 2014 & $-1,686$ & -195 & -9.98 & 18.61 & 0.5226 \\
\hline 2015 & 1,479 & 187 & 9.72 & & \\
\hline
\end{tabular}

Table 3 presents a summary of cross-elasticities of homicide for Jamaica, using hospitalization at the Victoria Jubilee hospital and homicide) for Jamaica from 2006-2015. Crosselasticities of homicide have changed from being lowly to highly responsive as well as from complementary to substitution. The positive elasticities indicate a complementary effect between hospitalization at Victoria Jubilee hospital and homicide (i.e., increases in homicide results in a rise in hospitalization at

the maternity hospital and vice versa). The two variables act in the same manner, which means that changes in homicide is associated with the shift in admissions at Victoria Jubilee hospital. The magnitude of the change is value of the elasticity ( $\eta$ $<1$ or $\eta>1)$. When elasticity is less than one $(\eta<1)$ it indicates that the relation between hospitalization and homicide is lowly responsive and vice versa for elasticities larger than one $(\eta>1)$. It follows, therefore, that homicide has an effect on admissions

to Victoria Jubilee hospital, using the positive elasticities, especially those greater than one.

Table 4: Cross-elasticities of hospitalization to deaths in Jamaica 2006-2015.

\begin{tabular}{|c|c|c|c|c|c|}
\hline Year & $\begin{array}{l}\text { Hospitalization Victoria } \\
\text { Jubilee }\end{array}$ & $\begin{array}{c}\text { Hospitalization at } \\
\text { Bellevue }\end{array}$ & $\begin{array}{l}\% \Delta \text { in admissions at } \\
\text { Victoria Jubilee }\end{array}$ & $\begin{array}{c}\% \Delta \text { in admissions at } \\
\text { Bellevue }\end{array}$ & $\eta$ \\
\hline 2006 & 14,101 & 18,960 & - & - & - \\
\hline 2007 & 15,846 & 20,550 & 12.38 & 8.39 & 1.4757 \\
\hline 2008 & 14,928 & 19,966 & -5.79 & -2.84 & 2.0386 \\
\hline 2009 & 16,635 & 18,855 & 11.43 & -5.56 & -2.0550 \\
\hline 2010 & 15,885 & 21,503 & -4.51 & 14.04 & -0.3210 \\
\hline 2011 & 15,888 & 16,926 & 0.02 & -21.29 & -0.0009 \\
\hline 2012 & 16,452 & 16,998 & 3.55 & 0.43 & 8.3451 \\
\hline 2013 & 16,895 & 15,427 & 2.69 & -9.24 & -0.2913 \\
\hline 2014 & 15,209 & 18,146 & -9.98 & 17.62 & -0.5662 \\
\hline 2015 & 16,688 & 18,157 & 9.72 & 0.06 & 160.4190 \\
\hline
\end{tabular}


Table 4 presents a summary of cross-elasticities of hospitalization to deaths. Over the studied period, deaths have substantially influenced hospitalization at Victoria Jubilee hospital in 2015 compare to $2014(\mathrm{n}=160.4>1)$. Furthermore, over the 10-year period, there were four times those hospitalizations at Victoria Jubilee hospital highly associated with the changes in deaths 2007, 2008, 2012 and 2015. However, there are years in which admissions at Victoria Jubilee hospital lowly respond to changes in death, suggesting that deaths had little to no influence on admissions of pregnant women to the maternity hospital. In 2011 over 2010, deaths overall had no effect on admissions at Victoria Jubilee.

Figure 1 depicts scatter plots of hospitalization at Victoria Jubilee hospital and homicide along a super-imposed function. On examination of (Figure 1), there is a cycle of hospitalization and homicide representing the peaks and troughs. The peaks and troughs suggest that there is a delayed effect of homicide on births. Using OLS, no linear correlation existed between admissions to the Victoria Jubilee hospital and homicide,

$\mathrm{F}[1,8]=0.081, \mathrm{P}=0.783>0.05$. The relationship between admissions at the national maternity hospital and homicide is best fitted by polynomial function, Equations (2) and (3):

$$
\begin{gathered}
\mathrm{V}=\mathrm{f}(\mathrm{H})(2) \\
\mathrm{V}=\beta 0+\beta 1 \mathrm{H}+\beta 2 \mathrm{H} 2+\beta 3 \mathrm{H} 3+\beta 4 \mathrm{H} 4+\beta 5 \mathrm{H} 5+\beta 6 \mathrm{H} 6+\beta 7 \mathrm{H} 7
\end{gathered}
$$

Where $\mathrm{V}$ is admissions (or hospitalization) to the national maternity hospital (i.e. Victoria Jubilee Hospital; $\mathrm{H}$ is homicide; $\beta 0$ is constant and $\beta 1-7$ are constants for each homicide component. Equation (3) accounts for $100 \%$ of the data points.

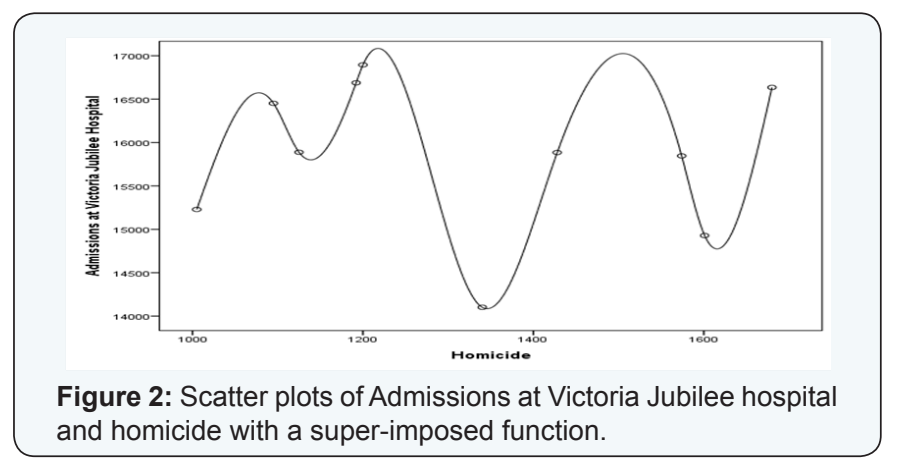

Figure 2 shows scatter plots of hospitalization at Victoria Jubilee hospital and deaths. Generally, deaths do not have a positive effect on the admissions of pregnant women being hospitalization at Victoria Jubilee hospital in Jamaica. Using OLS, no linear correlation existed between the two aforementioned variables, $\mathrm{F}[1,8]=1.646, \mathrm{P}=0.235>0.05$, Thus, correlation is a curvilinear one which is best fitted by a 3-degree polynomial function (Equations 4,5)

$$
\begin{aligned}
& V=f(D)(4) \\
& V=\beta_{0}+\beta_{1} D+\beta_{2} D^{2}+\beta_{3} D^{3}(5)
\end{aligned}
$$

Where $\mathrm{V}$ is admissions (or hospitalization) to the national maternity hospital (i.e. Victoria Jubilee Hospital; D is death; $\beta_{0}$ is constant and $\beta_{1-3}$ are constants for each death component. (Equation 5) accounts for $29.9 \%$ of the data points, which is a strong model.

Table 5: OLS of deaths on homicide 2005-2015.

\begin{tabular}{|c|c|c|c|c|c|}
\hline & & & \multirow{2}{*}{ Beta } & t & P value. \\
\cline { 1 - 3 } Constant & 11816.1 & 2764.9 & & 4.274 & 0.003 \\
\hline Homicide & 5.085 & 2.059 & 0.658 & 2.470 & 0.039 \\
\hline
\end{tabular}

By way of OLS, a linear correlation existed between deaths and homicide in Jamaica, $\mathrm{F}[1,8]=6.100, \mathrm{P}=0.038<0.05$, with the relationship between a positive one (Table 5). The squared $\mathrm{R}$ for the OLS was 0.433 and this indicates a strong model. It means that $43.3 \%$ of the data are explained by linear model (Equation 6). Although the linear function is a strong one, it is best explained by a curvilinear function, R2 $=0.806$ or $80.6 \%$. (Figure 3) depicts a cubic function or a 3-degree polynomial function between deaths and homicide for Jamaica, (Equation 7).

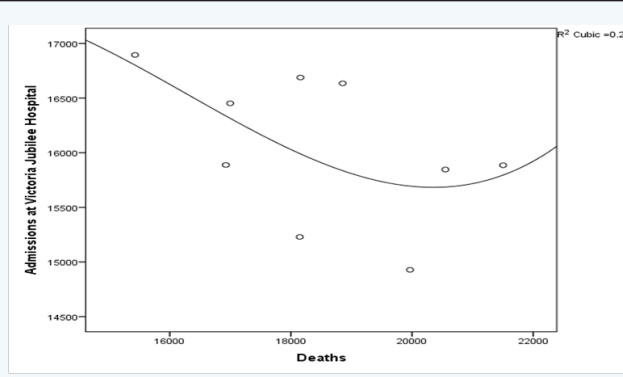

Figure 3: Scatter plots of Admissions at Victoria Jubilee hospital and deaths with a super-imposed function.

$$
\begin{aligned}
& D_{t}=f\left(H_{t}\right)(6.1) \\
& D_{t}=\alpha+\beta_{1} H_{t}(6.2) \\
& D_{t}=11,816+5 H_{t}(6.3)
\end{aligned}
$$

Where Dt is deaths in time period $\mathrm{t}$; $\mathrm{Ht}$ is homicide in time period $t ; \alpha$ is a constant and $\beta_{1}$ is the coefficient of Ht or the slope

$$
\begin{aligned}
& D=f(H)(7) \\
& D=\beta_{0}+\beta_{1} H+\beta_{2} H^{2}+\beta_{3} H^{3}
\end{aligned}
$$

Table 6 presents cross-elasticities between admissions at Victoria Jubilee hospital influencing hospitalization to the national psychiatric hospital in Jamaica (Bellevue Hospital) over a 10-year period. During that timeframe, there have been occasions when pregnant women who were hospitalized at the Victoria Jubilee hospital later became patients at the national psychiatric hospital. Those findings highlight the psychology of birth for women and the psychiatric effects on some women following childbirth is reflected by data for 2009 over 2008, 2010 over 2009, and 2012 over 2011. This means that birth is inducing psychiatric behavior among some pregnant women, but that psychiatric disorders are infrequently highly responsive to changes in the hospitalization of pregnant women. 


\section{Psychology and Behavioral Science International Journal}

Table 6: Cross-elasticities of hospitalization in Jamaica 2006-2015.

\begin{tabular}{|c|c|c|c|c|c|}
\hline Year & $\begin{array}{c}\text { Hospitalization } \\
\text { Victoria Jubilee }\end{array}$ & $\begin{array}{c}\text { Hospitalization at } \\
\text { Bellevue }\end{array}$ & $\begin{array}{c}\% \Delta \text { in admissions } \\
\text { at Victoria Jubilee }\end{array}$ & $\begin{array}{c}\% \Delta \text { in admissions } \\
\text { at Bellevue }\end{array}$ & $\eta$ \\
\hline 2006 & 14,101 & 1,110 & - & - & - \\
\hline 2007 & 15,846 & 965 & 12.38 & -13.06 & -1.06 \\
\hline 2008 & 14,928 & 972 & -5.79 & 0.73 & -0.13 \\
\hline 2009 & 16,635 & 1,087 & 11.43 & 11.83 & -3.03 \\
\hline 2010 & 15,885 & 1,045 & -4.51 & -3.86 & -445.89 \\
\hline 2011 & 15,888 & 957 & 0.02 & 3.97 & 1.12 \\
\hline 2012 & 16,452 & 995 & 3.55 & -0.40 & -0.15 \\
\hline 2013 & 16,895 & 991 & 2.69 & 1.41 & -0.14 \\
\hline 2014 & 15,209 & 1,005 & -9.98 & -1.09 & -0.11 \\
\hline 2015 & 16,688 & 994 & 9.72 & & \\
\hline
\end{tabular}

Using OLS regression, no linear correlation existed between hospitalization to the psychiatric hospital in Jamaica (Bellevue) and the national maternity hospital (Victoria Jubilee), $\mathrm{F}[1,8]=0.724, \mathrm{P}=0.419$. With the linearity assumption violated, curvilinear models were examined and it was found that 3-degree polynomial is a strong fit for the data, $\mathrm{R} 2=0.509$, (Equation 10) and (Figures 4-7).

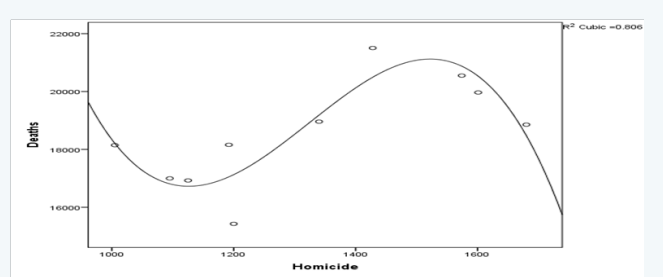

Figure 4: Scatter diagram of death and homicide on a superimposed function

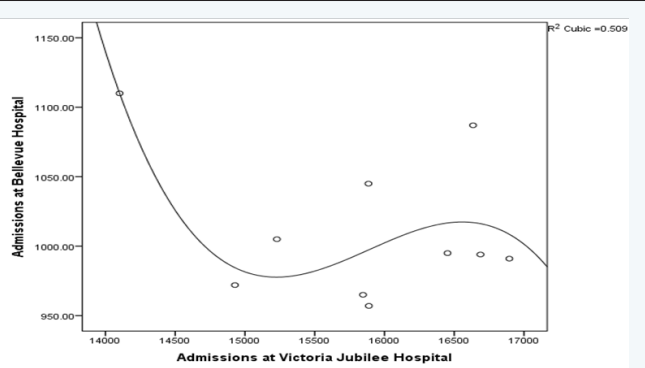

Figure 5: Scatter plots of admissions at Psychiatric and Maternity Hospitals on a super-imposed function

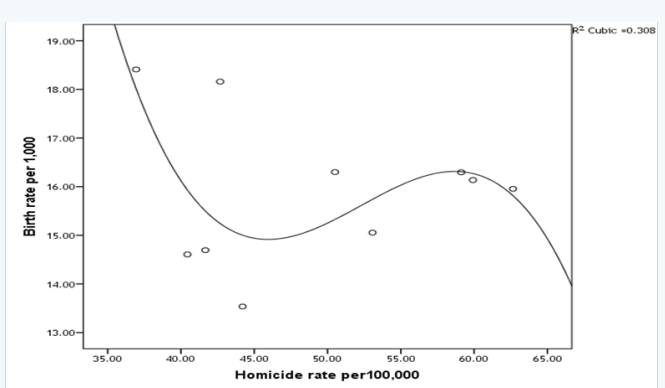

Figure 6: Scatter plots of Birth rate and homicide rate, superimposed on a curvilinear function

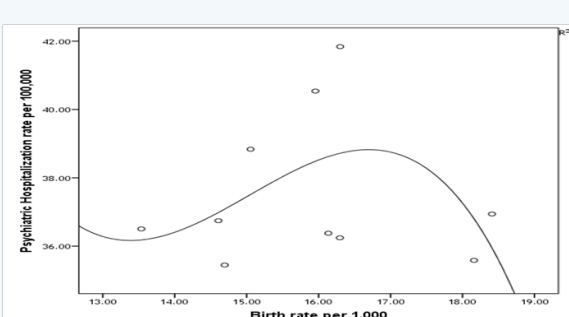

Figure 7: Scatter plots of psychiatric hospitalization rate and birth rate, superimposed

$B=f(H)(9)$

$\mathrm{B}=\beta_{0}+\beta_{1} \mathrm{~V}+\beta_{2} \mathrm{~V}^{2}+\beta_{3} \mathrm{~V}^{3}(10)$

Where $\mathrm{B}$ is admissions at the national psychiatric hospital in Jamaica (Bellevue); $\mathrm{V}$ is admissions at the national maternity hospital (Victoria Jubilee); $\beta_{0}$ is a constant and $\beta_{1-3}$ are coefficients.

\section{Birth and Homicide rates}

Using OLS regression, no linear statistical correlation existed between birth rate per 1,000 and homicide rate per 100,000 $\mathrm{F}[1,8]=0.039, \mathrm{P}=0.848>0.05$. However, the relationship is a curvilinear one, which account for $30.8 \%$ of the data points and this is a relatively strong model. This is expressed in (Equation 12):

$$
\begin{aligned}
& R=f(H)(11) \\
& R=\beta_{0}+\beta_{1} H+\beta_{2} H^{2}+\beta_{3} H^{3}
\end{aligned}
$$

Where $\mathrm{R}$ is birth rate per 1,000 of mid-year population in Jamaica; $\mathrm{H}$ is homicide rate per 100,000 mid-year populations; $\beta_{0}$ is a constant and $\beta_{1-3}$ are coefficients.

\section{Birth and Psychiatric Hospitalization rates}

Using OLS regression, no linear statistical correlation existed between birth rate per 1,000 and psychiatric hospitalization rate per $100,000-\mathrm{F}[1,8]=0.000, \mathrm{P}=0.994>0.05, \mathrm{R} 2=0.000$. However, the relationship is a curvilinear one, which account for $24.2 \%$ of the data points and this is a moderate associative model. The model means that birth is influenced by psychiatric 


\section{Psychology and Behavioral Science International Journal}

hospitalization; this is expressed in (Equation. 14):

$$
\begin{aligned}
& B=f(R)(13) \\
& B=\beta_{0}+\beta_{1} R+\beta_{2} R^{2}+\beta_{3} R^{3}(14)
\end{aligned}
$$

Where $\mathrm{R}$ is birth rate per 1,000 of mid-year population in Jamaica; $B$ is psychiatric hospitalization rate per 100,000 midyear populations; $\beta_{0}$ is a constant and $\beta_{1-3}$ are coefficients.

\section{Discussion}

The issue of the induced birth is widely studied, especially in health literature. While the issue of natural birth is highly preferred over induced labor, induction is a reality for many pregnant women because of medical problems, psychiatric orders or other issues that are considered as part of the decisionmaking for induction. It is not easy for a pregnant woman to agree to induction; however, a life threatening issue may influence the decision Lothian [27]; Wang et al. [28]. The issue of induction of birth has been clinically examined because of the vulnerability of women during pregnancy, treatment approaches and the rationale of childbirths to be a natural thing for women. There is a psychopathology of pregnancy that has never been explained by homicide and other deaths, which is examined in this paper. This study found that homicide as well as other deaths has an effect on induction of birth, suggesting that pregnant women in Jamaica are affected by the psychology of murders more than other types of deaths.

Not only is there is psychology of homicide or homicide psychology that includes evolutionary, biological, environmental and theoretical perspectives Richard-Devantoy et al. [29]; Martin \& Wilson [30]; Bancroft [31]; Buss \& Duntley [32]; Daly \& Wilson [33,34]; Nisbeth [35]; Smith \& Zahn [36]; but it is accounting for induced birth among pregnant women in Jamaica. Jamaica is among developing nations with the most murders and Bourne and colleagues refer it as the health pandemic Bourne et al. [37]; yet no study has been done on it effect on births.

This paper has empirically shown that homicide accounts for a significant number of hospitalization at the national maternity hospital, Victoria Jubilee hospital. The findings also revealed that 1) pregnancy is affecting psychosis; 2) homicide is influencing admissions at a maternity institution; 3) the relationship between homicide and maternity hospitalization of pregnant women is a cyclical one \& 4) admissions at the psychiatric hospital in Jamaica is sometimes highly responsive to pregnant women hospitalized at the maternity institution. Such revelations, from this empirical study, mean that pregnancy is not only about birth at full-term, it is also associated with increased psychiatric conditions (i.e. postpartum psychological disorders), induced births, and that homicide has a psychiatric delayed effect on pregnancy.

This means that pregnant women who reside in violent crime communities, especially exposed to murder or having a family murdered, are must be given pharmacologic treatment during pregnancy because of the psychiatric disorder associated with homicide on pregnancy. The Massachusetts General Hospital [38] forwarded that it has been found some women who become depressed or anxious, experienced bipolar disorder and other psychiatric disorders during pregnancy, which explains the hospitalization of pregnant women to psychiatric hospitals in this study. While pregnancy is associated with myriad of psychiatric disorders Carter [39]; Zuckerman et al. [40]; Santvana et al. [41], homicide is one of the explanations of the negative psychological state of pregnant women.

The present research revealed a curvilinear relationship between birth rate and homicide rate, which is contrary to established literature Pickett et al. [42]; Koppensteiner \& Manacorda [15]. It is established in the literature there is a strong positive linear correlation $(\mathrm{r}=0.95, \mathrm{P}<0.001$ in the United States; $r=0.74, \mathrm{P}<0.001$; internationally) between homicide rate and adolescent birth rates Pickett et al. [42]. The current work has established a cyclical pattern between admissions of pregnant women to the maternity hospital in Jamaica and homicide, suggesting that time effect of homicide on pregnancy, which was not recognized by the literature. The cyclical function provides an explanation that murders does not immediately affect psychological state of pregnant women and so does the pregnancy on their mental health. The change in the mental health status of pregnant women is also documented in a study which found lower birth weight of infants when their mothers' were exposed to violence Torche \& Villarreal [43] assisting in the explanation of effect of homicide on birth. Hutto opined that the closer a woman and her fetus were to a homicide did not linearly affect the birth outcomes of the fetus. There was also little difference between birth outcomes of mothers residing in low crime and high crime areas Hutto [44].

The non-linearity between homicide and outcome of pregnancy is also supported by this study; but Hutto stops short of explaining what emerged from the data. Therefore, the researchers claimed that homicide is inducing some births in Jamaica and that the delayed effect future birth outcomes. Furthermore, because the society is unable to remove the exposure of violence from the landscape, especially experienced by pregnant women, care must be taken by health care practitioners to identity these women who may expose to these traumatic situations for the purpose of future treatment even when there is no sign of mental health disorders. The psychology of homicide or homicide psychology has more than a psychological effect on pregnant woman as study showed physiology of homicide on the human immune system Segerstrom \& Miller [45].

It is Segerstrom \& Miller [45] perspective that provide the evidence that there is a lower birthweight of infants when their mothers were exposed to violence \& Bourne [46] empirically established a significant relationship between decline births and homicide. Thus, pregnant women are at increased risks of postpartum psychological disorders Bydlowski [4], physical changes in their bodies as well as to their unborn child as well 
as delayed effect of exposure to homicide. This research concurs with the literature that birth is inducing psychiatric disorder $\mathrm{Xu}$ et al. [6]; Bydlowski [4]; Doucet et al. [47]; Jones \& Smith [48]; Sit et al. [49]; but this paper goes further to show that association is a curvilinear one.

This study also demonstrated that there is a completely different reaction of pregnant women towards homicide than to other type of deaths. The psychology of homicide is, therefore, different from the psychology of other deaths and this is captured in the functions of this study. Clearly, pregnant women have a different susceptible to homicide than to other deaths as there is greater delay effect of former than the latter and this adds to the health literature on postpartum psychological disorders. The time effect of homicide is longer than that for other deaths and so this new reality requires more work as the data hereby cannot examine this phenomenon.

The time effect of homicide on pregnant women would add more to the health care literature as medical practitioner in treating their patients will be able to identity this issue and correctly diagnose the vulnerability of pregnant women to violence, particularly homicide. Time effect is nothing new in health literature as Sorenson, Wiebe \& Berk [50] showed that legalized abortions (or homicide of infants) were statistically associated with a significant decline in homicide in subsequent years, suggesting that psychology to human's behavior is more than a temporal one and extend into years afterwards, which is what is occurring among Jamaican pregnant women who are exposed to homicide [51-55].

\section{Conclusion}

Homicide has a different effect on the mental health status of pregnant women than other type of deaths. There is empirical evidence herein that homicide is inducing births and that this effect was not identified before this study. The delayed effect of homicide on pregnancy must be taken into health care treatment and clinical work, particularly because it is difficult to eliminate all violent exposure from pregnant women. Outside of the psychiatric effect of homicide on pregnancy, there is a psychiatric disorder associated with pregnancy and that its effect is a delayed one.

\section{References}

1. Statistical Institute of Jamaica (STATIN) (2016) Demographic statistics, 2015. STATIN, Kingston, UK.

2. Hill R C, Griffiths WE, Judge GG (2001) Undergraduates econometrics $\left(2^{\text {nd }}\right.$ edn), John Wiley and Sons, USA.

3. Bellevue hospital (2016) Brief history of Bellevue.

4. Bydlowski S (2015) Postpartum psychological disorders: Screening and prevention after birth, Guidelines for clinical practice. J Gynecol Obstet Biol Reprod 44(10): 1152-1156.

5. Baldur-Felskov B, Kjaer SK, Albieri V, Steding-Jessen M, Kjaer T, et al (2013) Psychiatric disorders in women with fertility problems: results from a large Danish register-based cohort study. Human Reproduction 28(3): 683-690.
6. Xu F, Sullivan EA, Li Z, Burns L, Austin MP, et al. (2014) The increased trend in mothers' hospital admissions for psychiatric disorders in the first year after birth between 2001 and 2010 in New South Wales Australia. BMC Women's Health 14: 119.

7. Crawford DM, Trotter EC, Hartshorn KJS, Whitbeck LB (2011) Pregnancy and Mental Health of Young Homeless Women. The American Journal of Orthopsychiatry 81(2): 173-183.

8. Gold LH (2002) Postpartum disorders in primary care: diagnosis and treatment. Prim Care 29(1): 27-41.

9. Thornton D, Guendelman S, Hosang N (2010) Obstetric Complications in Women with Diagnosed Mental Illness: The Relative Success of California's County Mental Health System. Health Services Research 45(1): 246-264.

10. Burke KC, Burke JD, Rae DS, Regier DA (1991) Comparing age at onset of major depression and other psychiatric disorders by birth cohorts in five US community populations. Archives of General Psychiatry 48(9): 789-795.

11. National Institute for Health (2015) Mental health problems and pregnancy.

12. Gallagher J (2012) Premature birth linked to worse mental health.

13. Nosarti C, Reichenberg A, Murray RM, Cnattingius S, Lambe, MP (2012) Preterm birth and psychiatric disorders in young adult life. Archives of General Psychiatry 69(6): E1-E8.

14. Valenca AM, de Moraes TM (2006) Relationship between homicide and mental disorders. Bras. Psiquiatr 28(2): S62-S68.

15. Koppensteiner MF, Manacorda M (2015) Violence and Birth Outcomes: Evidence From Homicides in Brazil.

16. Cohen J, Cohen P (1983) Applied multiple regression/correlation analysis for the behavioral sciences ( $2^{\text {nd }}$ edn), Lawrence Elbraum Associates, New Jersey, USA.

17. Hu TW (1982) Econometrics: An introductory analysis (2 $2^{\text {nd }}$ edn). University Park Press, Maryland, USA.

18. Lewis-Beck M (1980) Applied regression: An introduction. Sage, London, UK.

19. Maddala GS (1992) Introduction to econometrics (2 ${ }^{\text {nd }}$ edn). Macmillan Publishing company, New York, USA.

20. Divaris K, Vann WF, Baker AD, Lee JY (2012) Examining the accuracy of caregivers' assessments of young children's oral health status. Journal of the American Dental Association 143(11): 1237-1247.

21. Hinkle DE, Wiersma W, Jurs SG (2003) Applied Statistics for the Behavioral Sciences ( $5^{\text {th }}$ edn), Houghton Mifflin, Boston, USA.

22. Mukaka M (2012) A guide to appropriate use of Correlation coefficient in medical research. Malawi Medical Journal: The Journal of Medical Association of Malawi 24(3): 69-71.

23. Evans JD (1996) Straightforward Statistics for the Behavioral Sciences. Brooks/Cole Publishing, California, USA.

24. Howell DC (2007) Fundamental statistics for the behavioral sciences. California, USA.

25. Howell DC (2010) Statistical methods for psychology ( $7^{\text {th }}$ edn), California, USA.

26. Howitt D, Cramer D (2011) Introduction to statistics in psychology (5th edn). Pearson, Harlow, UK.

27. Lothian JA (2006) Saying "No" to Induction. The Journal of Perinatal Education 15(2): 43-45.

28. Wang M, Dorer D, Fleming M \& Catlin E (2004) Clinical outcomes of near-term infants. Pediatrics 114(2): 372-376. 
29. Richard-Devantoy S, Olie JP, Gourevitch R (2009) Risk of homicide and major mental disorders: A critical review. Encephale 35(6): 521-30.

30. Martin D, Wilson M (1997) Crime and Conflict: Homicide in Evolutionary Psychological Perspective. Crime \& Justice 22: 51-100.

31. Bancroft C (1898) Subconscious homicide and suicide; their physiological psychology. American Journal of Insanity 55(2): 263 273.

32. Buss DM, Duntley JD (2006) The evolution of aggression. In: M Schaller \& J A Simpson (Eds.), D T Evolution and social psychology, Psychology Press, New York, USA, pp. 263-285.

33. Daly M, Wilson M (1988) Aldine de Gruyter, New York, USA.

34. Daly M, Wilson M (1997) Crime and conflict: Homicide in evolutionary psychology perspective. Crime \& Justice 22: 51-100.

35. Nisbett RE (1993) Violence and U.S. regional culture. American Psychologist 48(4): 441-449.

36. Smith MD, Zahn M (2004) Homicide: A sourcebook of social research, Sage, California, USA.

37. Bourne PA, Hudson-Davis A, Sharpe-Pryce C, Francis C, Solan I, et al. (2015). Homicide, rape and carnal abuse in Jamaica 1970-2013: The New Health Pandemics. International Journal of Emergency Mental Health and Human Resilience 17(2): 588-597.

38. Massachusetts General Hospital (2015). Psychiatric Disorders During Pregnancy.

39. Carter D (2005) Psychiatric disorders in pregnancy. BCMJ 47(2): 9699.

40. Zuckerman B, Bauchner H, Parker S, Cabral H (1990) Maternal depressive symptoms during pregnancy, and newborn irritability. J Dev Behav Pediatr 11(4): 190-194.

41. Chang J, Berg CJ, Saltzman LE, Herndon J (2005) Homicide: A Leading Cause of Injury Deaths Among Pregnant and Postpartum Women in the United States, 1991-1999. American Journal of Public Health 95(3) 471-477.

42. Pickett KE, Mookherjee J, Wilkinson RG (2005) Adolescent Birth Rates, Total Homicides, and Income Inequality In Rich Countries. American Journal of Public Health 95(7): 1181-1183.
43. Torche F, Villarreal A (2014) Prenatal exposure to violence and birth weight in Mexico: Selectivity, exposure, and behavioral responses. American Sociological Review 79(5): 966-992.

44. Hutto N (2012) The relationship between proximity to homicide and birth outcomes. Doctor of Philosophy thesis, Columbia University, New York, USA.

45. Segerstrom SC, Miller GE (2004) "Psychological stress and the human immune system: a meta-analytic study of 30 years of inquiry." Psychological Bulletin 130 (4): 601-630.

46. Bourne P (2012) Births, economic growth, mortality and murder in developing country. Health 4(2): 46-55.

47. Doucet S, Jones I, Letourneau N, Dennis CL, Blackmore ER (2011) Interventions for the prevention and treatment of postpartum psychosis: a systematic review. Archives of Women's Mental Health 14(2): 89-98.

48. Jones I, Smith S (2009) Puerperal Psychosis: Identifying and caring for women at risk. Advances in Psychiatric Treatment 15: 411-418.

49. Sit D, Rothschild AJ, Wisner KL (2006) A Review of Postpartum Psychosis. Journal of Women's Health 15(4): 352-368.

50. Sorenson SB, Wiebe DJ, Berk RA (2002) Legalized Abortion and the Homicide of Young Children: An Empirical Investigation 2: 239-256

51. Hall J, Wynter E (2003) Kingston Public Hospital: The High Seat of Medicine in Jamaica, Pelican Publishers, Kingston, UK.

52. Institute of Psychiatry, Psychology and Neuroscience (2013) New mothers (puerperal psychosis).

53. Santvana S, Shamsah S, Firuza P, Rajesh P (2005) Psychiatric disorders associated with pregnancy. J Obstet Gynecol India 55(3): 218-227.

54. South East Regional Health Authority (SERHA) (2016b) Victoria Jubilee Hospital: Fact Sheet. Kingston, UK.

55. United Nations (UN), Permanent mission of Jamaica to the United Nations. 